\title{
Using Internet of Things and Distributed Ledger Technology for Digital Circular Economy Enablement: The Case of Electronic Equipment
}

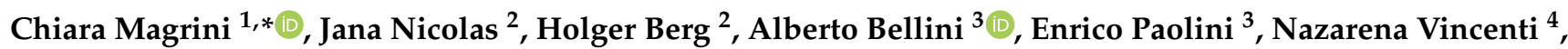 \\ Luca Campadello $^{4}$ and Alessandra Bonoli ${ }^{1}$ \\ 1 Department of Civil, Chemical, Environmental and Materials Engineering (DICAM), \\ University of Bologna, 40131 Bologna, Italy; alessandra.bonoli@unibo.it \\ 2 Wuppertal Institute for Climate, Environment and Energy, 42103 Wuppertal, Germany; \\ jana.nicolas@wupperinst.org (J.N.); holger.berg@wupperinst.org (H.B.) \\ 3 Department of Electrical, Electronic and Information Engineering "Guglielmo Marconi" (DEI), \\ University of Bologna, 47522 Cesena, Italy; a.bellini@unibo.it (A.B.); e.paolini@unibo.it (E.P.) \\ 4 Erion Compliance Organization, 20154 Milano, Italy; nazarena.vincenti@erion.it (N.V.); \\ luca.campadello@erion.it (L.C.) \\ * Correspondence: chiara.magrini7@unibo.it
}

Citation: Magrini, C.; Nicolas, J.; Berg, H.; Bellini, A.; Paolini, E.; Vincenti, N.; Campadello, L.; Bonoli, A. Using Internet of Things and Distributed Ledger Technology for Digital Circular Economy Enablement: The Case of Electronic Equipment. Sustainability 2021, 13, 4982. https:// doi.org/10.3390/su13094982

Academic Editors:

Gianmarco Bressanelli,

Federico Adrodegari, Daniela

Cristina Antelmi Pigosso and Vinit Prida

Received: 31 March 2021

Accepted: 27 April 2021

Published: 29 April 2021

Publisher's Note: MDPI stays neutra with regard to jurisdictional claims in published maps and institutional affiliations.

Copyright: (c) 2021 by the authors. Licensee MDPI, Basel, Switzerland. This article is an open access article distributed under the terms and conditions of the Creative Commons Attribution (CC BY) license (https:/ / creativecommons.org/licenses/by/ $4.0 /)$

\begin{abstract}
Nowadays, high expectations are set for a digitally enabled circular economy (CE), to enhance resource efficiency. Tracing, tracking, and storing information is most important for this. In this paper, the application of Internet of Things (IoT) and Distributed Ledger Technology (Blockchain) are hence discussed by presenting the case of professional Electrical and Electronic Equipment (EEE) in Italy. Within the context of CE, prevention of electronic waste (WEEE) is extremely relevant as it is a fast-growing waste stream, and the products contain environmentally damaging substances as well as valuable and rare materials. The use of a proper combination of IoT and blockchain can help the producers to keep control on products until EEE end-of-life, while promoting CE strategies and supporting decision-making. Based on the outcomes of five interviews conducted in 2019 to companies of the EEE sector, potential improvements in the EEE end-of-use management are discussed. After providing the definition of requirements for both the technical solution and its testing are provided, three solution variations and the related business models are created and presented, as well as considerations on their environmental and economic impacts. The study shows how digital technologies can support the appropriate and circular management of EEE products and WEEE.
\end{abstract}

Keywords: circular economy; digitalization; IoT; blockchain; distributed ledger technology; electric and electronic equipment; WEEE; sustainable business model; BCoT; corporate social responsibility

\section{Introduction}

Circular economy (CE) is a mandatory breakthrough in material economics for climate and economic reasons. Industry is responsible for about one third of global greenhouse gas (GHG) emissions. Materials account for about $75 \%$ of the carbon budget allocated to industry in a Paris agreement compliant scenario, at European level [1]. CE strategies that reduce extraction, prolong product and material lifetime, and prevent waste can contribute significantly to a reduction of GHG emissions and environmental damage. At the same time, re-use and recycling of materials reduce costs and impact on the environment. Nevertheless, the circularity gap currently straining the environment and the world economy suggests that progress towards $\mathrm{CE}$ is not happening yet: the global economy is only $8.6 \%$ circular, while just 2 years ago it was $9.1 \%$ [2]

High expectations are set for a digitally enabled CE [3-5]: digital technologies have been identified as fundamental enablers for CE business models [6], as well as an important 
opportunity to strengthen productivity and resilience of businesses, but also reinforce sustainability and more efficient industrial systems. To unlock the tremendous opportunities that the CE holds, the coordination of material and information flows is crucial: information about quantity and quality of products and their material content need to be collected and retained to enable practices like predictive maintenance, refurbishment, or recycling. Through the concept of "digital twin", digital technologies enable keeping the data together with materials in the cycle and make it possible to use waste as a resource [7]. Digital solutions can provide real-time data about an item's location, condition, and availability; increase traceability of materials; ease access to products and services; and make processes more convenient and effective [8]. Moreover, data analytics can serve as a tool to predict product health and wear, reduce production downtime, schedule maintenance, order spare parts, and optimize energy consumption [9]. CE benefits from digital, online platforms and technologies, which strengthen connections between supply-chain actors. In a circular business model it usually is not one company that closes the loop, but the ecosystem that does [4]. Vertical and horizontal integration of stakeholders along the product lifecycle starting with the raw material manufacturer and finishing with the end-consumer will increase resource efficiency and improve the information availability and analysis within the supply chain [10].

Most literature highlights a research gap, recognizing the need for more research and case studies that link CE and digital technologies [3,9,11-14]. With the ambition to contribute to a filling of this gap, this paper discusses the implementation of digital CE strategies by analyzing an innovative approach to a digital tracking solution for professional electrical and electronic equipment (EEE) and for waste from electrical and electronic equipment (WEEE or e-waste) management. The digital solution has been investigated in a real-life case study and tested at laboratory scale, with the aim of being transparent, secure, trustable, reliable, independent from centralized authorities, and able to provide full control on the entire value chain. Besides improving the waste management, this might enable the implementation of new management solutions and business models, which have been created and discussed.

The relevance of the transition of EEE sector to a circular economy is related to the significant environmental and social impacts of its products, which are resource intensive in terms of materials and energy, both in the production and usage phases, as well as in their end-of-life. The high innovation frequency of the digital economy and decreasing prices of many electrical and electronic devices, coupled with multiple device ownership; the growth of cloud computing services; the uptake of artificial intelligence; the increased use of mobile, wireless, and connected products; and the planned obsolescence of digital end devices leads to an increase of almost 2 million metric tons per year in global electrical and electronic waste [15]. Proper recovery and treatment processes (i.e., depollution, disassembly, reuse of components, shredding, sorting, recycling of secondary raw materials, recovery or disposal) of e-waste pose a challenge to waste management systems, not only because of its quantity, but also for its variety and composition [16], meaning a high content of both precious and hazardous materials. From one side, many components and useful materials can be valorized and recovered. From another side, given that EEE contains toxic additives or substances of concern identified as "hazardous" (e.g., mercury, lead, brominated flame retardants, etc.), landfilling, incineration or littering may result in adverse effects on the environment and human health. Inappropriate disposal and recycling of WEEE can expose people and the environment to toxic chemicals when used products are not treated in formal recycling centres $[17,18]$. Significant ethical issues are posed by the illegal and improper exportation of e-waste toward developing countries, where child labor and uncontrolled management and dismantling conditions imply hazardous pollution and risks for health of exposed workers [17]. Proper EEE production and WEEE management support producers and companies in their corporate social responsibility and policies [19].

Thus, the implementation of CE strategies is pivotal: EEE and WEEE need a dedicated management system, which can include logistics and installation of new equipment as well 
as reuse, repair, disassembly, transport, and management of end-of-life equipment. While for household appliances good examples of end-of life management practices already exist, professional WEEE management systems suffer from several shortcomings due to their complexity. This study focuses on tracing professional EEE and WEEE generated in Italy, to create proper product and material streams. Indeed, numbers published in 2019 by the Italian clearing house for WEEE management showed that out of more than 235,000 tons of professional EEE put on the market during the previous 3 years (2016-2018), about 110,000 tons were confirmed to be managed generating a collection rate equivalent to $46.80 \%$ [20], calculated as the amount of collected WEEE in relation to the amount of EEE put on the market in the three preceding years. Thus, more than $53 \%$ of the professional WEEE are not declared by the responsible actors for the end-of-life management. Probably, this happens because the standard used for the management is not compliant with the legislative requirement. Thus, the aim of this paper is to investigate the role of digital solutions in solving this issue and in increasing the circularity rate of the EEE sector.

\section{A Digital Approach to Control WEEE}

\subsection{Background: The Professional EEE Sector in Italy: Challenges to Enable a Circular Economy}

The development of innovative and reliable solutions to manage the professional EEE and WEEE through digital technologies must necessarily start from the current models applied by the EEE producers and the challenges emerging from such models. Five Italian companies (EEE producers, providers, or distributors) were consulted (Table 1) with dedicated semi-structured face-to-face interviews, conducted in June-November 2019, aimed at exploring their professional EEE market, the actors involved along the supply chain, their appliances' tracing system, and the related performance. Collected information, including the actors involved along the value chain, their relationships, needs, issues, and shortcomings, have been used as a key input for the subsequent activities, including technical activities (e.g., technical system requirements) and business-modelrelated activities.

Table 1. The interviewed companies: main characteristics.

\begin{tabular}{ccccc}
\hline Company & Role & Professional EEE & EEE Locations & Contract \\
\hline Company 1 & EEE provider & Coolers & Bars, restaurants & loan for use \\
Company 2 & EEE producer & Washer disinfectors & Hospitals, dentists, laboratories & end-user ownership \\
Company 3 & EEE producer & Appliances & Shops, kitchen of restaurants & end-user ownership \\
Company 4 & EEE producer & Professional coffee machines & Coffee bars & loan for use \\
Company 5 & EEE distributor & TVs, appliances. & Hotels, cinemas, conference halls & end-user ownership \\
\hline
\end{tabular}

${ }^{1}$ Beverage company, which grants coolers on free loan to businesses (bars, restaurants).

According to the results of the interviews, professional EEE users generally require higher service levels than household users, while the price is a less critical factor.

All companies agree on the fact that the EEE/WEEE value chain is long, complex, and often not confined inside national boundaries. Starting from the raw material extraction phase, passing through the production and distribution step, and ending with the waste management activities, several actors are involved along the life cycle of the electronic and electrical devices, and they are often geographically distributed in different locations. Moreover, EEE lifespan is variable (sometimes very long). Therefore, it is often very difficult for EEE producers, who are responsible by law of proper WEEE management, to keep control until EEE end-of-life.

To face these challenges, many EEE producers have individually implemented different management systems themselves. Tracing of professional EEE is most often performed in a centralized manner directly by the company that is responsible for end-of-life disposal and recycling (typically the manufacturer). The objective is not limited to verifying and updating the current position of the item, but also to obtain information about its correct use. Although such an approach is effective in cases where a relatively small number of 
very expensive appliances shall be traced, in others where the number of items to be traced is large, a considerable fraction of them gets lost. Moreover, this solution does not always permit the company to avoid corporate representatives travelling and visiting customers, in order to check the condition of EEE or for marketing reasons.

The diagram in Figure 1 shows the ideal flowchart at the end-of-use phase of EEE, from the waste hierarchy perspective (Directive 2008/98/EC, Article 4, and confirmed by the amended Waste Framework Directive (EU) 2018/851): after prevention, the most favorable option in the waste management should be reuse, above recycling and recovery. This hierarchy is broadly consistent with the idea that the main objective of the circular economy is to maintain the value of products, components, and materials at their highest level [21].

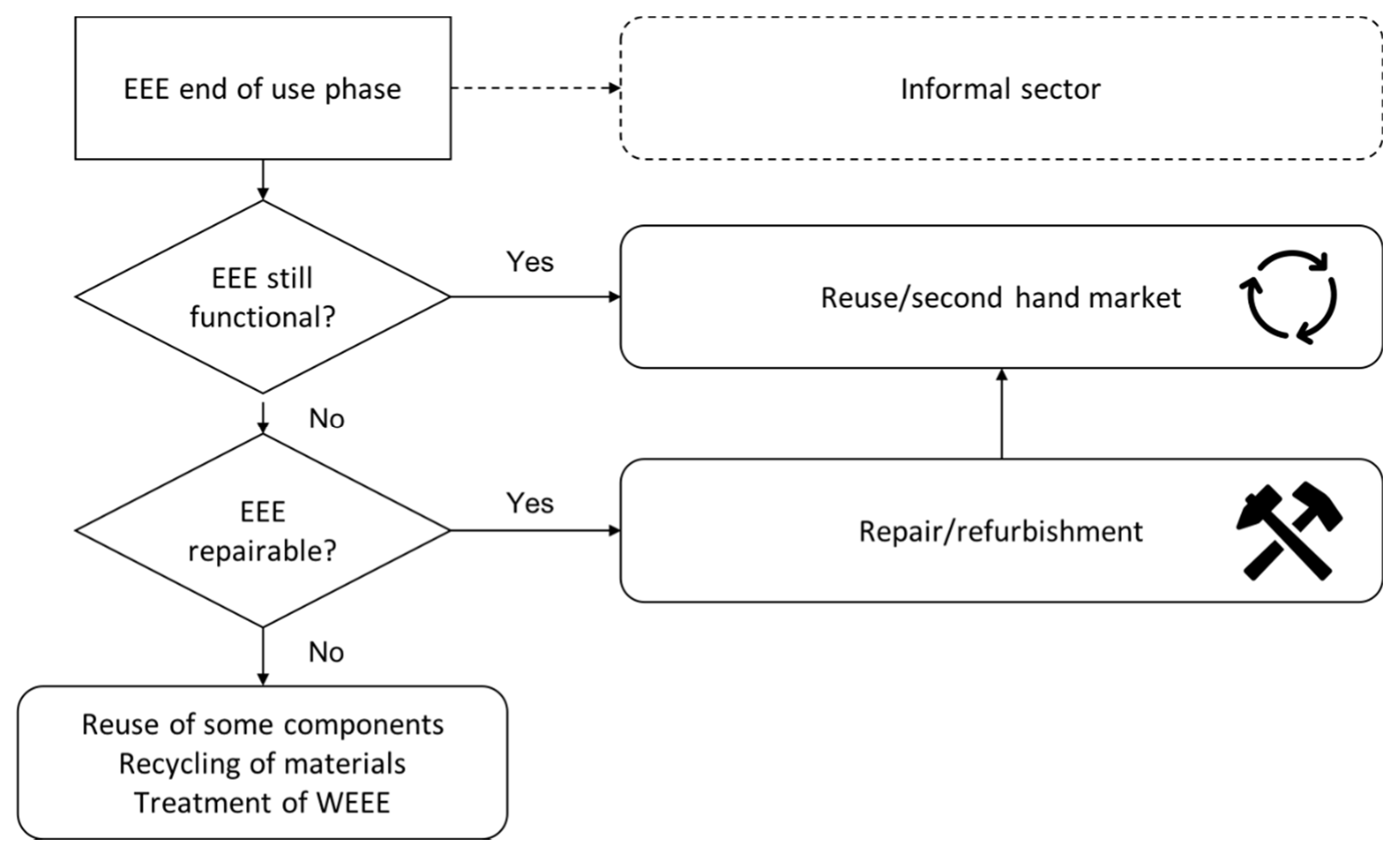

Figure 1. Flow chart for EEE end of use.

In accordance with regulations or guidelines regarding used equipment, the functionalities of the retrieved EEE must be tested. Based on the remaining functionality, different options should be decided upon how to deal with the equipment. Product reuse is preferred over product repair. If direct reuse or minor repairs/refurbishment are not feasible due to economic or functional barriers, the best option is to reuse as many parts and components as possible. If this is not possible, the recycling of the product on material level should be chosen.

The interviews have revealed that reuse is generally performed in the cases of companies that provide EEE in loans, since in this way the high residual value of the products is captured. Legislative limitations on the reuse of components have also been highlighted in one case (i.e., EEE for hospitals). Maintenance and repair are carried out in some cases by original equipment manufacturers, in other cases by third party firms. If possible, repair is performed in the place where the EEE is installed.

The diagram also shows through the dotted lines, the presence of an informal system. WEEE, which is ending up in the informal sector, is usually not managed according to environmental standards, but for example managed by informal operators interested in recovering only valuable materials such as copper, iron, aluminum, and precious metals, 
without taking care of other components or illegally exported outside EU. In the European Union in 2016, the total collection rate of WEEE was $49 \%$, calculated as the amount of collected WEEE in relation to the average amount of EEE put on the market in the three preceding years, 2013-2015 [22]; this suggests the presence of undocumented waste flows. Furthermore, it can be estimated that the potential release of GHG emissions from undocumented wasted fridges and air conditioners in Europe is equal to 12.7 metric ton carbon dioxide $\left(\mathrm{CO}_{2}\right)$ equivalents [15].

From an environmental and economic perspective, it is important to divert WEEE from being handled in the informal sector. Digital technologies can also be employed to prevent such a leakage and ensure their proper handling at the end of EEE use-phase. Finally, trustable information regarding the specifications of raw materials used in the production phase can be collected by ensuring the producer's compliance with several laws (e.g., REACH regulation, share of recyclates versus virgin materials used).

Thus, the challenge is to push a comprehensive distributed approach in the information management, with the objective to track professional EEE via:

- Data generated by the several actors operating along the professional EEE supply chain, including the manufacturer, logistic operators, customers, maintenance operators, and end-of-life treatment operators.

- Data collected in a traditional centralized manner, often by a corporate representative visiting customers and downloading information directly from the professional appliance.

- IoT data, autonomously generated by the professional appliances connected to the Internet and sporadically transmitting short data packets containing some relevant information, including geolocation information.

- Crowdsourcing data generated by people using personal devices, being turned in a source of massive data.

The last item is of particular interest for tracing of those professional appliances that are located in places constantly visited by customers. An example is represented by coolers or coffee machines installed in cafes. Overall, such a distributed approach, taking full advantage of a wide range of heterogeneous data, would strongly improve traceability and promote the correct end-of-life disposal.

To achieve this goal, several challenges need to be addressed, from development of efficient algorithms, e.g., based on artificial intelligence techniques, for analyzing a very large amount of available data sources, to collection and storage of data in a trustable and non-tamperable manner. Heterogeneous and distributed sensing systems call for interoperable solutions and data harmonization, as well as scalable solutions able to handle a large amount of information with intermittent data flows. Especially when people are engaged through a "neighborhood watch" approach, solutions are needed to handle unpredictable data traffic peaks and to filter and validate contents. Moreover, innovative circular business models are needed.

\subsection{From BC and IoT to BCoT the Emergence of a Digital Solution}

IoT and connected devices are everyday physical objects or devices that are connected to the Internet and can interact, even autonomously, with other smart objects or humanhandled devices. IoT allows to collect large amounts of data ("Big Data"), which can be analyzed with appropriate analytics. Big data can be analyzed to great benefit to better understand consumers and optimize supply chains and human resources to bring profound insights to decision-makers [10]. Moreover, it allows the improvement and innovation of existing evaluation theories and methods for environmental performance evaluation of the supply chain, promoting higher synergies and sharing among the involved actors, as well as providing scientific basis and guidance to formulate environmental protection policies [23]. According to the literature review performed in [6], IoT is considered one of the most important technologies able to support the transition to CE.

Distributed Ledger Technology (DLT) forms a second ingredient. It is better known as blockchain (BC) - a specific subset of DLT-and enables tracking and monitoring of 
incremental transactions and provenance of assets throughout their lifecycle even in an adversarial environment, where participants do not trust each other ex-ante. BC can be used to securely record and share information such as operating parameters, location, or energy consumption. Information can be stored in a decentralized way, which makes this technology a candidate to significantly disrupt the centralized regulatory compliance processes and transactions within the industry [24]. The CE can benefit from simultaneous cooperation and competition within the loop, adopting a decentralized principle of value creation and circulation as opposed to value creation and value appropriation [25]. BC can align supply chains with CE sustainability through traceability and transparency; it can make information about the origin of a product, processes and the parties involved in related transactions and logistics visible, traceable, and verifiable by all those in the supply chain, thus supporting the application of sustainability criteria for the selection of suppliers, vendors, materials, and products, as well as the design of more sustainable logistics networks and internal operations [26,27]. Therefore, a BC-based documentation of the product history increases transparency in the supply chain for $\mathrm{CE}$, providing information at the point of sale to build trust and security regarding transactions between the involved parties. Moreover, in the waste management sector, BC is expected to help in overcoming deficiencies of the current Extended Producers Responsibility (EPR) system, mainly due to the missing connection between the actual product sold by original equipment manufacturers in the market and the product recovered by the final processor [28]. Furthermore, it can be a source of intelligent accounting and verification systems in future applications $[10,29,30]$.

The advent of BC technology provides an unparalleled driver for peer-to-peer CE Business Models to thrive, enabling peer-to-peer transactions without any middlemen. This means that the consumers are not relegated to simple roles anymore, using, sharing and/or separating products or waste. On the contrary, they can transact and pay each other directly and securely through a decentralized, distributed network. Smart contracts trigger automatic enforcement and execution of payment mechanisms that assure everyone involved in the contract is compensated.

$\mathrm{BC}$ and IoT technologies together could provide efficient support to Industry 4.0, especially with reference to the typical challenges faced through the supply chain, such as traceability, automation, reliability, and transparency. As a matter of fact, traceability is one of the main challenges for manufacturers, administrations, banks, service providers, professionals, and several other actors [31]. Traceability improves transparency of transactions between parts needing mutual trust and using verifiable records. Tracing the history of a product, a record or a process through the entire supply chain is sometimes a hard task, especially when the supply chain involves several independent entities.

Several BC-based systems have already been deployed for tracing purposes along the supply chain. Several successful experiences and previous proposals were analyzed to have a clear understanding of the current status of the application of these technologies. Throughout this analysis, three of the existing cases have been considered particularly useful. The first solution is the one developed by Walmart in collaboration with IBM to track mangos and pork along the supply chain, with the purpose of ensuring complete traceability and to reduce the time needed to rebuild the value-chain of these two products [32]. The second solution is the one implemented by the shipping company Maersk, again in collaboration with IBM, aimed at reducing the amount of necessary paperwork along the supply chain of containers. The third considered experience is the one reported by the company Provenance to track tuna fish caught in Indonesia and ensure full traceability and transparency from the landing to factory and beyond.

Recently, the "Blockchain of Things" (BCoT), featuring a cooperation of BC technology and the IoT ecosystem, has emerged as a new paradigm for tracing applications, proving itself very effective in maintaining data in an efficient, reliable, trustable, and safe way. BCoT systems are particularly attractive to collect data from all the actors involved in the manufacturing, distribution, and end-of-life management of a product [33-35]. BC 
nodes can potentially be installed at every key point of the supply chain, providing the architecture of a distributed but shared database where all actors can trustfully store and share data, in a tamper-proof way. In the framework of the same architecture, IoT devices can be used to automate exchange of key data, relieving human intervention wherever data can potentially be tampered or modified. This way, data gathered from the chain nodes can be considered reliable and enhanced transparency is achieved along the whole supply chain.

\section{A Digital Solution Space: Using BCoT to Solve the EEE Challenge}

\subsection{Requirements and Design of the of BC System to Address the EEE Challenge}

The performed analysis led to the specification of a set of general requirements for a BC system dedicated to EEE and WEEE management. As remarked in previous works (e.g., [36]) as a first requirement, the nature of the BC should be permissioned. A permissioned BC allows introducing an access control mechanism, which is essential to allow accepting transactions only from authorized users. Such users include the several players active along the professional EEE supply chain (e.g., manufacturers, retailers, users), each interfacing its own enterprise resource management (ERP) system with the BC, as well as IoT devices autonomously sending transactions and participants generating crowdsourcing data. The BC shall exhibit different segments: a "public" section, accessible to all actors, private sections, and even sections where users have reading but not writing permissions.

The system should be highly fault tolerant and should have the capability to recover from failures of sub-parts in a reasonable amount of time; this can be achieved exploiting the $\mathrm{BC}$ to store different equal copies of the same data, with the possibility to re-synchronize nodes after a break. Other general requirements include: (i) the low cost per transaction, directly linked with the energy cost of the consensus algorithm; (ii) the capability of the $\mathrm{BC}$ (along with its consensus algorithm) to achieve a high transaction throughput, where blocks have to be committed with a low latency after being sent to the nodes. Clearly, these efficiency requirements do not fit well with consensus algorithms typical of public BC systems, such as Bitcoin, requiring high computational power and characterized by high latency in committing blocks and low transaction throughput.

Among the several considered solutions and development environments, Hyperledger Fabric was selected as a suitable option to meet the above-mentioned requirements. One of the key features of Hyperledger Fabric is the possibility to create permissioned BC systems with several channels on the same BC node, with different access levels and permissions. Remarkably, channels can be made completely separated and isolated from each other even if they are on the same node. One or more channels can be allocated to a specific actor along the supply chain, to separate sensible data, used for internal purposes, from data that can be made public, such as the ones used to rebuild the value chains over different interactors, shared with all participants. Notably, multiple smart contracts (or chain codes) may run on the same channel, potentially supporting a great variety of business models, allowing automation of transactions and operations on the chain, such as checking the conditions that must be met to tag a product as "valid" along the chain.

The employed consensus algorithm is Raft, natively implemented on ordering nodes (or simply orderers) and based on an election strategy: in the configuration phase the orderers agree to elect a master among them and subsequently all transactions are submitted to the master and then broadcast to all orderers. For each transaction, orderers simulate the result and then send the batch to the peer; if the result of the transaction committed by the latter is equal to the simulated one, the transaction is considered valid, otherwise the block is rejected. Tests conducted by IBM have revealed how up to 25 channels can be operated on the same node without observing any significant performance degradation, each organization participating in the system being associated with one or more channels. This means that all peers, orderers, and certificate authorities belonging to that organization operate the $\mathrm{BC}$ for the corresponding channel(s). In particular, peers maintain a copy of the $\mathrm{BC}$; orderers are in charge of ordering the transactions and send them in batches to 
the peers to commit on the BC; and certificate authorities generate certificates for admins, users, and for orderers and peers.

In Hyperledger Fabric, two types of data can be stored: (i) On-chain Data, transactional data saved in the chain as blocks with a unique id and a hash; and (ii) Off-Chain Data, such as photos, videos, pdf files or other text files. This leads to the possibility to use the chain not only as a database for data coming from the IoT devices, but also as a valid tool to save all files normally needed to be printed or exchanged in other non-centralized ways along the supply chain (such as bills, delivery notes, contract, etc.). A valid approach may be to use a database to save the file and store only its hash in the chain.

All peers have always the same copy of the chain, and consistency of data is ensured every time. Although Hyperledger Fabric is a permissioned BC framework, in principle it allows implementing public BCs. To this aim it is necessary to create certificates for a single user, which can be reused by anybody to commit a transaction on the network. Considering the flexibility offered by the above-mentioned channels, it is possible to run a private and a public $\mathrm{BC}$ on a single node.

To assess the technical feasibility of the envisaged system, an experimental testbed has been implemented. The experimental activity allowed testing of the BC system interoperated with IoT technologies at the laboratory scale. Details on the testbed and on its results are reported in Appendix A.

\subsection{Solutions}

Business models and their innovation are crucial to allow companies to create value through the implementation of CE principles. While the value created along forward supply chains is quite evident-raw materials are processed into products that are sold, the "value retained" of a used product, its components, and its materials is not as easy to determine in the current linear economy. Indeed, as highlighted by [37], closed-loop activities for $\mathrm{BC}$ are not at the forefront of adoption: the analysis of 10 cases from five major industries showed that these companies tend to focus on the forward supply chain activities and not necessarily reverse logistics, which is an option for sourcing reusable goods.

Based on the technical solution developed, three solution variations have been identified to support the EEE producers to maintain the control of appliances along different phases of the life cycle and to support a CE at the same time. Focusing on the integration of value added and value retained [38], the first variation supports repair and reuse, while the second one adds recycling. The third variation investigates the potential involvement of final customers, if EEE products are located in places accessible to them and environmental and economic benefits derive. The use of a business model canvas approach [39] has ensured the completeness, consistency, and validity of the approach. The business model canvases for all the variations are reported in Appendix B.

The underlying assumptions for each of the variations presented below are that every professional EEE product is equipped with an identifier (tag) and eventually some sensors (e.g., GPS, gyroscope, accelerometer, humidity sensor, temperature sensor) and that different stakeholders can read/write information about the products location and condition throughout the products lifecycle. In the creation of the three variations, an incremental approach has been used, meaning that each solution variation increases the number of stakeholders involved and the amount of data tracked in the BC system. The perspective of the EEE manufacturers has been assumed.

\subsubsection{Variation 1-Blockchain-Based Solution for Repair and Reuse}

In the solutions derived, producers and/or providers are the actors involved, as well as repair centers (Figure 2). They use a BC system in order to collect data regarding the lifetime of products/components, use phase, maintenance, and repair cycles and geo-localization of EEE. The expected effect is a substitution for new products and virgin materials, which can save money for manufacturers. Sensors might be a support in deciding if reuse, preparation for reuse, or remanufacturing are possible. A proper management of WEEE is more likely, 
thanks to geo-localization. For EEE users, a potential extension of the EEE lifespan is possible. This might allow them to save money too. Innovation is mainly at the product level. The business model canvas for this variation is reported in Table A1.

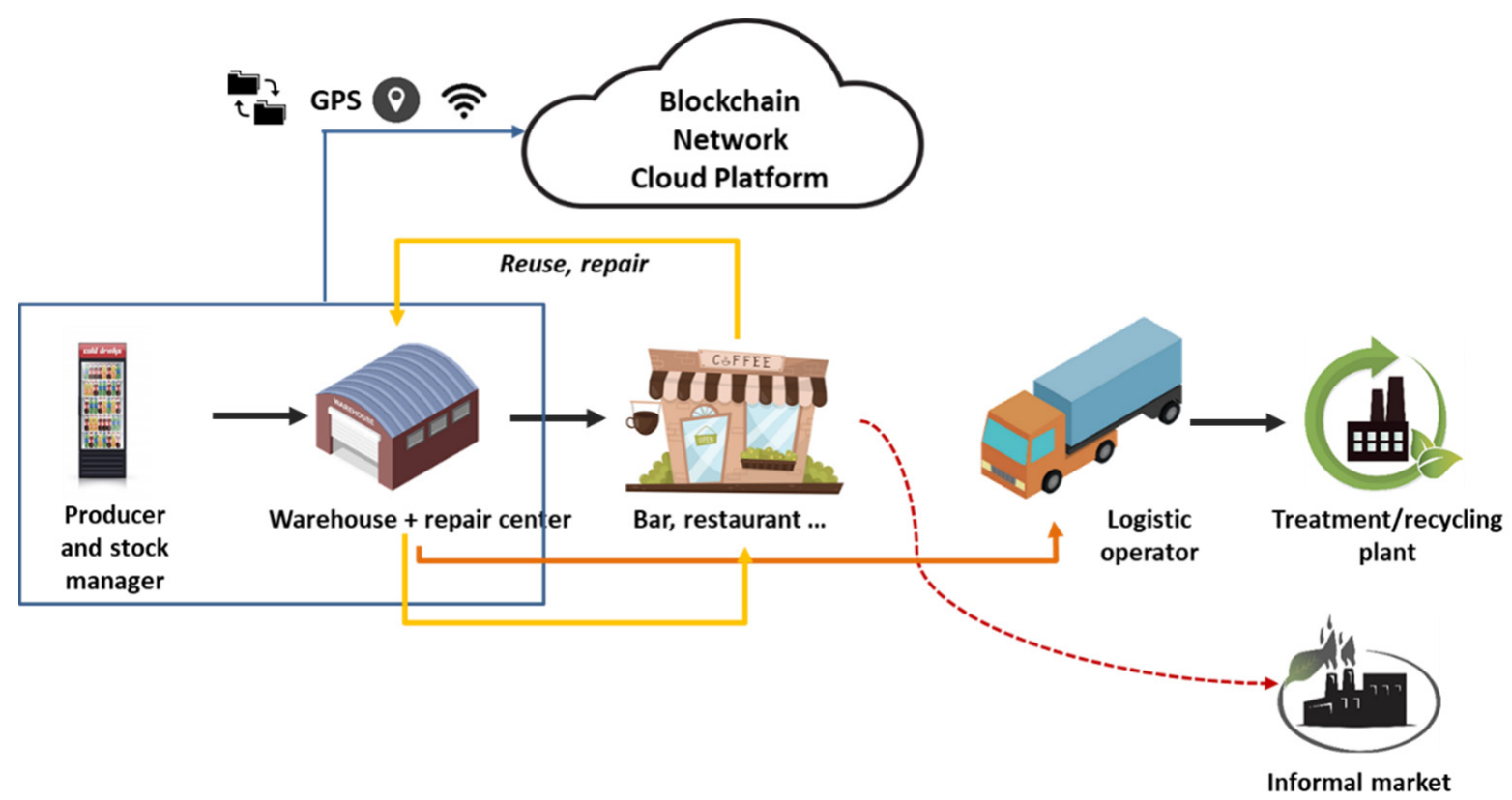

Figure 2. Variation 1-blockchain-based solution for repair, and reuse.

\subsubsection{Variation 2-Blockchain-Based Solution for Repair, Reuse, and Recycling}

While the repair and maintenance, reuse and redistribution, and refurbishment and remanufacturing CE business models contribute to slowing resource loops by retaining the product value, recycling CE business models seek to retain the material value by closing resource loops [38].

In this variation, the involvement of more stakeholders than in variation 1 is assumed. WEEE treatment operators, EEE/WEE carriers, and recycling operators are provided with access to different data in different levels of details, relevant for them and their tasks (Figure 3). The aim is to create a closed-loop system: at the end-of-life stage, functioning products/components are reused, other components are remanufactured, and materials are recycled.

In particular:

- WEEE treatment operators could be interested in data about the components and the materials, and the presence of environmentally damaging substances. These might help them in deciding if reuse, preparation for reuse, remanufacturing or material recycling is possible. Moreover, data on the quantity of WEEE would help them in planning for adequate storage and resources.

- $\quad$ EEE/WEE carriers could be interested in data about the physical characteristics of EEE/WEEE to optimize the logistics (for example, dimensions and weight).

- Recycling operators could be interested in data about the materials. Moreover, data on the quantity of WEEE would help them in planning for adequate storage and resources.

The object of innovation is not only the product, but innovative models at organizational level are also enabled. The Business model canvas for this variation is reported in Table A2. 


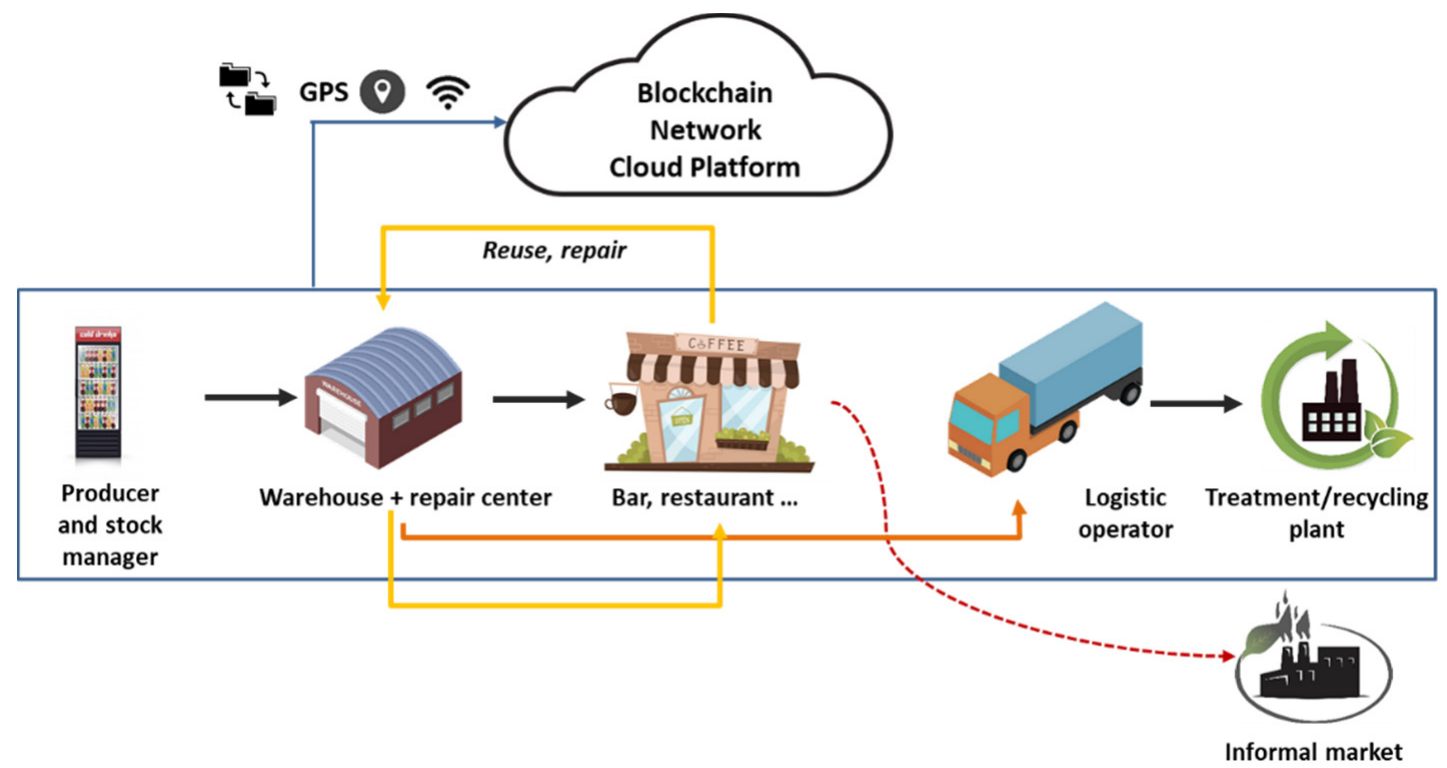

Figure 3. Variation 2-blockchain-based solution for repair, reuse, and recycling.

3.2.3. Variation 3-Blockchain-Based Solution for Professional EEE and WEEE Management, with Smart-Contract and Involvement of Consumers

In this variation, consumers visiting the places where EEE is located can send a picture of the EEE itself, if it is accessible; this picture might provide further information, which cannot be gathered through IoT (Figures 4 and 5). The picture (validated by an image processing software) might be sent to the BC system, together with other information tracked by the sensors (e.g., inner temperature, energy consumption, number of times that the door has been opened). This solution might allow companies to avoid the visits performed by corporate representatives.

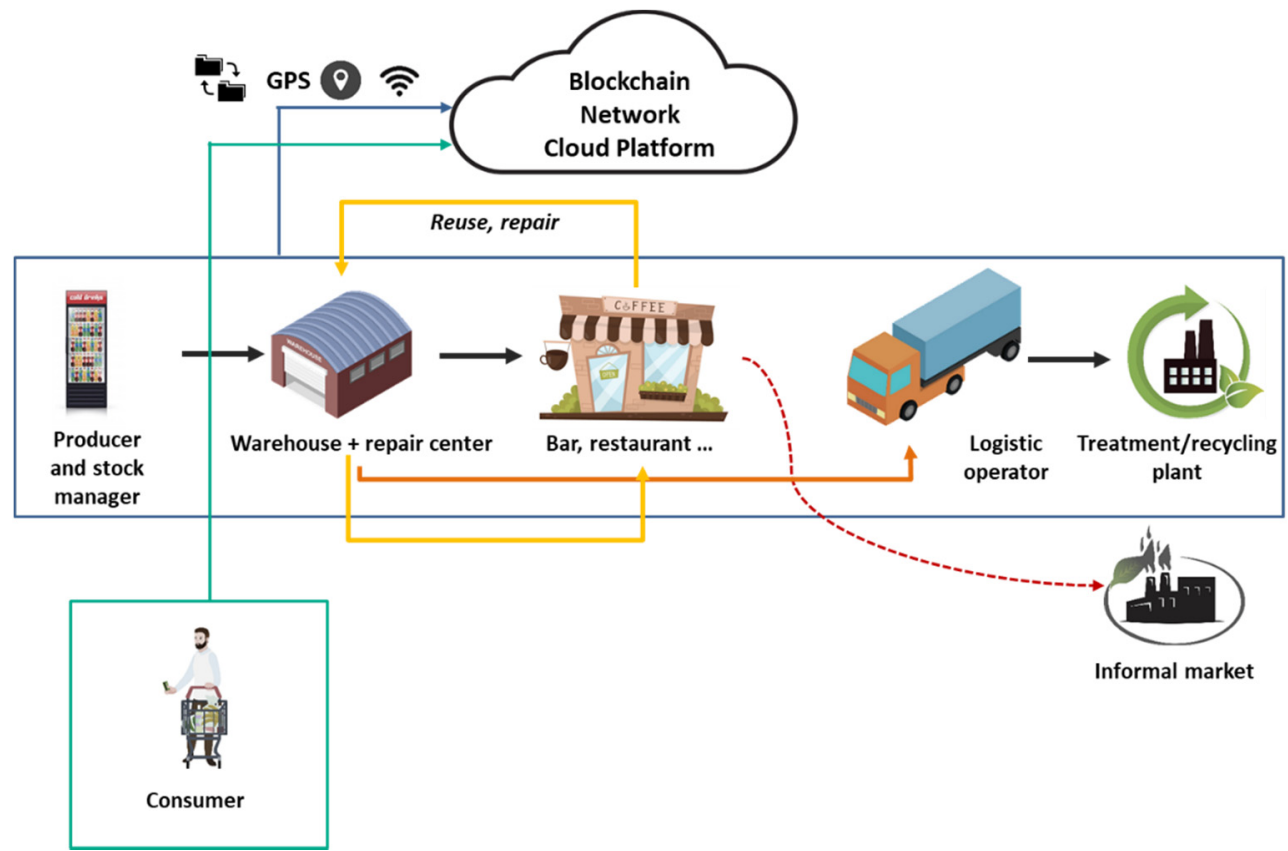

Figure 4. Variation 3-blockchain-based solution for professional EEE and WEEE management, with smart-contract and involvement of consumers. 


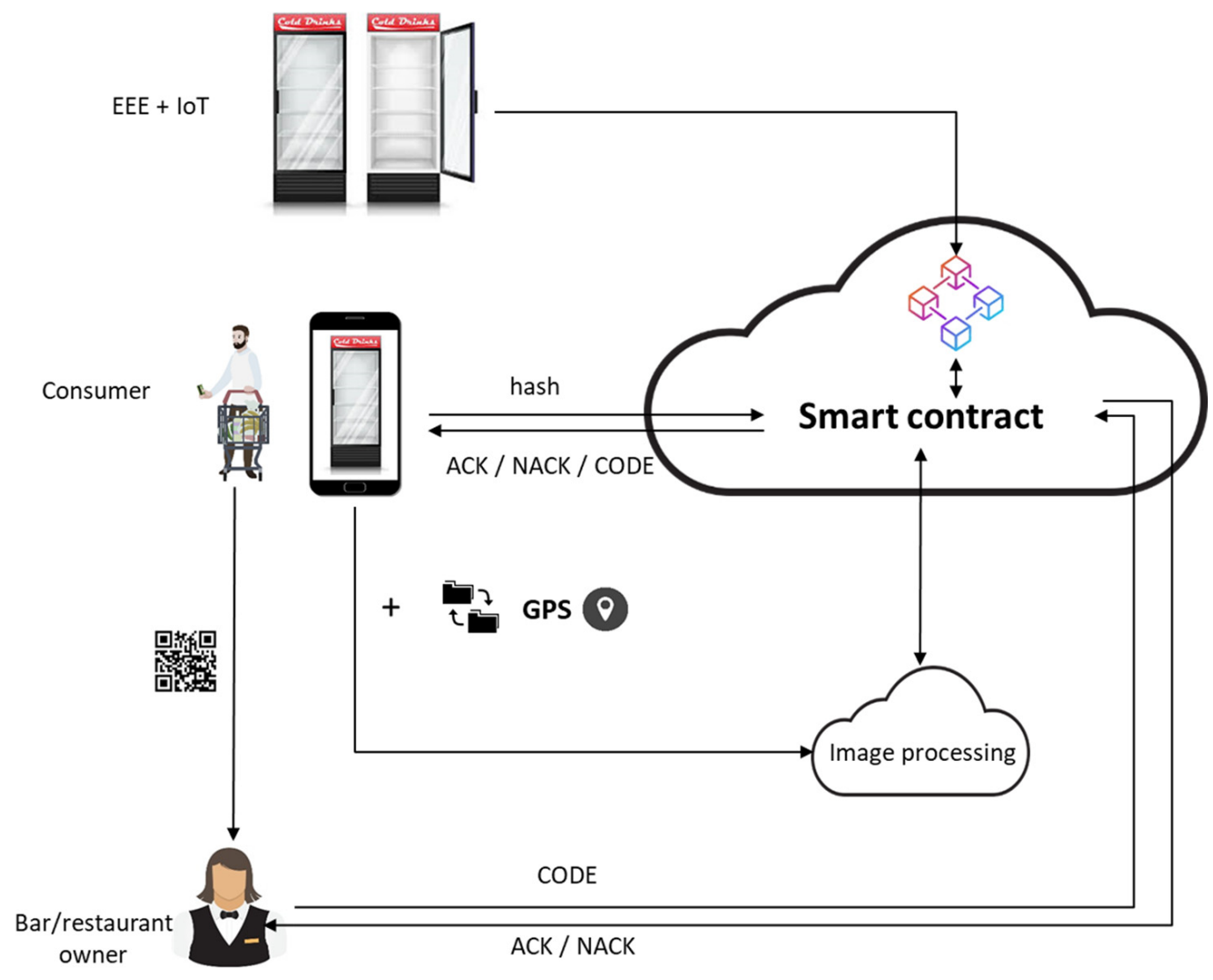

Figure 5. Variation 3-details on the smart contract function.

A system of incentives for consumers should be designed to ensure their support in tracking the required information, as well as eventually a system to involve the owner of the business activity that uses the EEE: in some cases, this solution can enable a potential innovative marketing solution for the owner of the business activity himself.

In order to transfer information onto the BC that the consumer cannot see (e.g., energy consumption), information from the sensors could for example be transferred to the consumers device and complement the information gathered by the costumer. In this way, the consumers can become a channel for the transmission of other information, recorded by IoT nodes (using for example NFC technology). The exchange of information with the consumers might be regulated by a smart contract.

Alternatively, the professional EEE product could be connected to the (mobile) internet in another way, e.g., through using SIM cards or Wi-Fi. The Business model canvas for this variation is reported in Table A3.

\subsection{Further Elaborations}

An additional solution variation could be created, by assuming that the producer retains the ownership of the product, receiving a fixed fee (for example, monthly) from the users, according to the "product-as-a-service" model. The services offered to users might include the maintenance and updates of devices, and also the ability to exchange a product for a different or newer model. EEE providers and users benefit, as they pay for the service they require and use, and often receive a better service as the manufacturer has a greater interest in providing a product that lasts. The producer gets a regular income stream and can focus on improving the durability of the EEE and making them easily repairable, changing design processes from "design for marketing" to "design for remanufacture and reuse". In this way, waste prevention is pursued, through the extension of the utilization phase for items [40]. 
This model has a higher success potential in the case of professional EEE, compared to consumer EEE, because the users' need satisfied by professional EEE might be more long-lasting than one of the consumers. So, professional users are keen on creating a long-lasting relationship with the supplier. Furthermore, literature suggests that user behaviour can become less responsible when a product is not owned, leading to reduced efficiencies and increased wear of the product. Because people do not own the products in an access-based service, it is unlikely that they forge strong attachments to these products, and consequently, they may take less care of these products ([41-43]). This is less likely to happen in the case of professional users, as they need EEE for their business to run.

Another instrument to adjust the incentive for a user to return a device after it reaches the end of its expected lifetime could be the use of dynamic pricing, that can be related to, for example, time of use, condition, or location, as described in [44]. EEE could be restored and used again and again, offering the update-repair-recycle service free of charge to users and ensuring the return of the materials back into use.

If the user does not return EEE for update, repair or recycling, the monthly cost rises. This incentivizes the consumer to return the commodity for necessary updates or repairs that at this point are less costly to the brand owner and producer and ensure that its value is preserved with minimum effort. Additionally, this also means better value for the user and improved customer loyalty. If the user does not return the commodity at the expected end-of-life, the cost continues to rise until the commodity is returned for recycling. If the commodity is lost completely, the user pays a one-off payment, agreed in advance, and starts a new programme. The later the EEE is returned to the manufacturer, the greater the cost rises for the manufacturer due to the increased effort, materials, and energy required to restore the lost value [44].

\subsection{Considerations about Environmental and Economic Impacts of the Variations}

Besides advantages due to the avoided loss of materials, the proper management of WEEE is related with potential savings in equivalent carbon dioxide $\left(\mathrm{CO}_{2 \mathrm{eq}}\right)$ emissions. Moreover, an extension of EEE' lifetime might result in a decrease of $\mathrm{CO}_{2 \mathrm{eq}}$ emissions attributed to each EEE.

Environmental impacts due to BC energy consumption have to be carefully considered in all the variations. In variation 3, an estimation of the energy consumption of customers' devices should also be performed. The energy consumption of an IoT node could be assumed as not relevant for the environmental analysis, compared to the consumption of the EEE itself.

$\mathrm{CO}_{2 \text { eq }}$ emissions related to all the life cycles of digital devices should be evaluated, by assessing impacts in a life-cycle perspective, from the materials' supply to the end-of-life.

Moreover, since in many cases a corporate representative visits the EEE users, the potential $\mathrm{CO}_{2 \mathrm{eq}}$-savings from the reduction of travels of the employees should be quantified, as well as potential $\mathrm{CO}_{2 \mathrm{eq}}$-savings from the recycling process and from transport optimization (in variations 2 and 3).

From the economic point of view, potential savings are related to avoided cost for travels, avoided fines for non-compliance with the national legislation on WEEE management, and to recirculation of materials in the productive cycle. The cost of the BC and IoT system should be evaluated, including the cost of initial investment (design and purchase of sensors which are plugged in all EEE) and the operating costs (energy, maintenance).

Finally, it should be considered that this is a fast-developing environment, where important parameters like the BC validation technology can change quickly and alter the assessment dramatically.

In parallel, pressure on EEE producers rises, considering the reinforcement of EPR or the collection and recycling targets set by recent policies [45]. 


\section{Discussion}

Containing very valuable materials and posing dire environmental problems, WEEE for their very nature is an important challenge but also represents a perfect showcase for circularity. WEEE management is a perfect area where new technologies can be assessed and proved. The authors were able to show how a combination of IoT and DLT can lead to an improvement of a circularity for EEE with different impact based on the respective variations. The role of digital technologies in enabling $\mathrm{CE}$ already highlighted by literature is confirmed: creation of a traceable supply and use chain for EEE could help to prolong product lifetime and retain valuable materials, thus effectively creating a more resource efficient EEE (and WEEE) regime. The massive pollution and health damage created by WEEE could be drastically reduced. Moreover, the companies of this sector could strengthen their corporate social responsibility performance [19] by increasing the awareness of consumers and thus contributing to the evolution towards sustainable development.

While according to the review performed in [5], where the relation between the technological solutions and the main $\mathrm{CE}$ concepts employed (i.e., reduce, reuse, recycle and restore) is studied, IoT and BC are more relevant to the "reduce" CE concept; the solutions here proposed, based on a combination of both the technologies, aim at promoting reuse, repair, and recycle as well, by improving the reverse flows. In compliance with the waste hierarchy and the value retention principle [21], these strategies are implemented by the proposed variations adopting an incremental approach, thus starting from the most favorable options.

As described in the variations, different kinds of data can be stored and transferred thanks to BC technology:

- General data on product characteristics (e.g., dimension) can be used to optimize the logistics.

- Data regarding the lifetime of products/components, use phase, maintenance, and repair cycles can be used for enhancing the product design and for forecasting of spare parts demand. This can help to prevent reaching the premature end-of-use of the product.

- Data from the continuous traceability of materials, in terms of location, condition, and availability, might be used to facilitate the repair and maintenance of EEE.

- The geo-localization of EEE/WEEE guarantees the regulatory compliance, regarding WEEE management, e.g., in Italy.

- Information on the use of chemical substances in the product or its components can be embedded into the $B C$, too, and passed along the supply chain to the various interested parties or parties that need the information (e.g., customers, manufacturers, importers, and recyclers). Hence, $\mathrm{BC}$ technology can help producers to fulfil their responsibilities in regard to the REACH (Restriction of Hazardous Substances Directive 2002/95/EC) regulation, implemented in 2007.

- Eventually, information provided by consumers, as the picture of EEE.

It should be noticed that one of the interviewed companies was particularly interested in tracking the materials and components used to assemble the product, also involving the raw material manufacturers and taking advantage of digital solutions to effectively prove the compliance to legislative requirements. Thus, further research can investigate the feasibility of this application.

Moreover, BC can also help to ensure and assure the customers that child labor was not used, and human rights were protected in the production and supply chain process [25]. This is crucial in the EEE sector and deserves further analysis, considering that the enormous request of critical and strategic raw materials used in electronic devices have consequences in human rights and social impacts, because of supply systems and mining activities in crucial areas of the world, where continuing conflicts occur [46].

Further benefits might stem from the overcoming of impediments associated with copyright infringements, in the management of post-consumer disposal of e-waste and recycle, reuse, and remanufacturing processes, as outlined in [47].

In general, many technologically-enabled solutions contribute to circular business models (e.g., providing services instead of products), improving products (including design 
and production processes) and their end-of-life treatment (e.g., reuse, repair, remanufacturing, recycling, waste collection, and sorting). However, challenges still remain with regard to the development and scalability of solutions due to inter alia a lack of (public) investments, adequate regulatory framework, and/or sufficient market demand [48].

Obviously, a key to a successful transition towards CE is therefore going beyond the waste management perspective to integrate $C E$ principles across the life cycle. An integration of the complete supply chain will be necessary. The technologies here presented can be used to achieve these purposes. Nevertheless, merely establishing closed-loop supply chains is clearly inadequate; it is crucial that companies determine how to create value with such supply chains [38]. Effectively transforming existing value chains into value cycles requires a holistic view and design of circular ecosystems consisting of complementary value-generating actors, who not only share a vision of circularity, but are also ready to distribute profits in a way that ensures the long-term commitment of contributing actors; in this sense, digital technologies can enable and reinforce value cycles [49]. In the case here presented, for example, the potential savings of the recycling cost due to the improved tracing system should be distributed among the involved stakeholders in a proper way. As in many cases, EEE producers fulfil the obligation to keep control on the end-of-life of its products by joining a collective scheme through the payment of a fee. The role of the consortia, which are responsible for professional WEEE management in the promotion of these business models and in the creation of mechanisms for the distribution of generated value, might be subject to further research. Moreover, as adopters of new products and services, consumers-both business-to-customer and business-to-business-play a central role in the transition towards the CE. Their involvement should be rewarded. Digital technologies can help in both these activities. Finally, the adoption of "product-as-a-service" model and of dynamic pricing might be investigated [44], being an incentive for a more radical transition to "design for remanufacture and reuse" and waste prevention.

Implications for stakeholders thus specifically concern the further development, testing, adoption, and enablement of these technologies. It should be considered that the adoption of BC-based solutions has been mostly at the demonstration and piloting stage so far, as shown by [37]. Thus, these implementations still suffer from infrastructure challenges including failures of interoperability, technological security, and stability issues.

An important implication for policy makers is the enablement of such an infrastructure by support of technology development and standard setting, but also by the creation of an enabling and demanding legislation for WEEE treatment including the requirement of meticulous proofs of use and treatment.

One caveat remains: the efforts to digitally mitigate the WEEE-problem and the creation of an EEE CE must not environmentally overshoot the efficiency gains and the waste prevented. In other words, the measures taken need to be assessed, and rebound effects have to be avoided. Especially the potential energy-hungry nature of DLTs can be a concern here. If that proves successful, a much more sustainable electronic appliance regime can emerge.

Author Contributions: Conceptualization, C.M., J.N., H.B., A.B. (Alberto Bellini), E.P., N.V. and L.C..; methodology, C.M., J.N., E.P., N.V. and L.C.; software, E.P.; validation, H.B., A.B. (Alberto Bellini) and A.B. (Alessandra Bonoli); investigation, E.P., C.M., J.N., N.V. and L.C.; writing-original draft preparation, C.M., J.N., H.B., E.P. and N.V.; writing-review and editing, C.M., J.N., H.B., A.B. (Alberto Bellini), E.P., N.V., L.C. and A.B. (Alessandra Bonoli); visualization C.M., E.P. and N.V.; supervision, H.B., A.B. (Alberto Bellini) and L.C.; project administration, H.B., A.B. (Alberto Bellini), E.P., N.V. and L.C.; funding acquisition, H.B., A.B. (Alberto Bellini), E.P., N.V. and L.C. All authors have read and agreed to the published version of the manuscript.

Funding: This research is part of EIT Climate-KIC project BlockWEEE (Project ID: 190796) funded by the European Institute of Innovation and Technology (EIT), a body of the European Union, under H2020, the EU Framework Programme for Research and Innovation. This research was also supported by the Italian Ministry of Education, University and Research (MIUR), under program "Departments of Excellence (2018-2022)—Plastic DNA". 
Institutional Review Board Statement: Not applicable.

Informed Consent Statement: Not applicable.

Data Availability Statement: Not applicable.

Acknowledgments: The authors acknowledge Marco Giachin and Sergiu Popescu for their support in blockchain implementation and laboratory tests.

Conflicts of Interest: The authors declare no conflict of interest. The funders had no role in the design of the study; in the collection, analyses, or interpretation of data; in the writing of the manuscript, or in the decision to publish the results.

\section{Appendix A. Testbed Design and Results}

The testbed consisted of:

- Two PCs, each running a single Hyperledger Fabric BC node and a single channel, with two peers and four orderers. Each PC has the capability to process, validate, and store blocks, enhanced with fault tolerance and recovery methods.

- A number of IoT nodes, each implemented with Commercial Off-the-Shelf (COTS) hardware components and equipped with four low-cost sensors of different types; each IoT node collects measurement data from all its sensors, assembles a packet of data (in the form of a JSON message) with aggregate sensing information, and then transmits the packet wirelessly to a central node.

- A central node, again implemented with COTS hardware, that buffers packets and schedules their transmission, in the form of transactions, to the BC.

- A mobile application developed to simulate transmission of crowdsourcing information from participants' smartphones to the BC.

The choice to use a star topology for the IoT nodes (which does not mimic the architecture of the real system, where each IoT node should send data directly to the BC), in which all IoT stations are batched and linked with the central node, was dictated to allow the possibility to scale the network to a large number of nodes, with the only problem to investigate how many nodes can be batched, basing on the hardware used and the cost requirements. Regarding the developed mobile application, it features the possibility to read NFC tags IDs and to embed this information in the generated transaction. This way, assuming the NFC tag on in the professional appliance to be traced, it is possible to associate crowdsourcing data with the specific appliance.

With the described architecture, PCs featuring a dual-core Intel Celeron CPU and 8 GB of RAM were used.

A maximum achievable throughput approximately equal to 35 transactions per second for each node (specifically, 5 blocks per second with 7 transactions per block) was observed: beyond this value, errors on block commitment happened. Such errors may be ascribed to poor performance and parallelization capability of the employed processor. In fact, the consensus algorithm of Fabric requires the orderer to simulate every transaction before asking the peer to commit it; in this way the time needed to perform the necessary computation is doubled. Beyond the mentioned value the CPU used to work nearly at $100 \%$ of its capability; the result is a CPU throttling which causes a degradation in performance and errors on block commitment. Adoption of a more powerful CPU equipped with more cores, performing parallel computing and processing of blocks, allowed achieving substantially higher transaction rates. In particular, a transaction rate of 100 transactions per second was achieved using a quad-core Intel CPU. The testbed proved to be highly reliable, being now active for several months and tolerating rates of transactions close to the maximum one for periods of several days without crashes. This leads to the capability of undergoing several malfunctions that will not affect the whole network. The high level of replication ensured by the $\mathrm{BC}$, where all nodes store the same copy of all data, leads to the possibility of removing or adding nodes dynamically to perform maintenance or to scale the system, re-synchronizing the node in several seconds to have the same copy of the chain on all peers. 


\section{Appendix B. Business Model Canvas of the 3 Variations}

Table A1. Variation 1-Business model canvas.

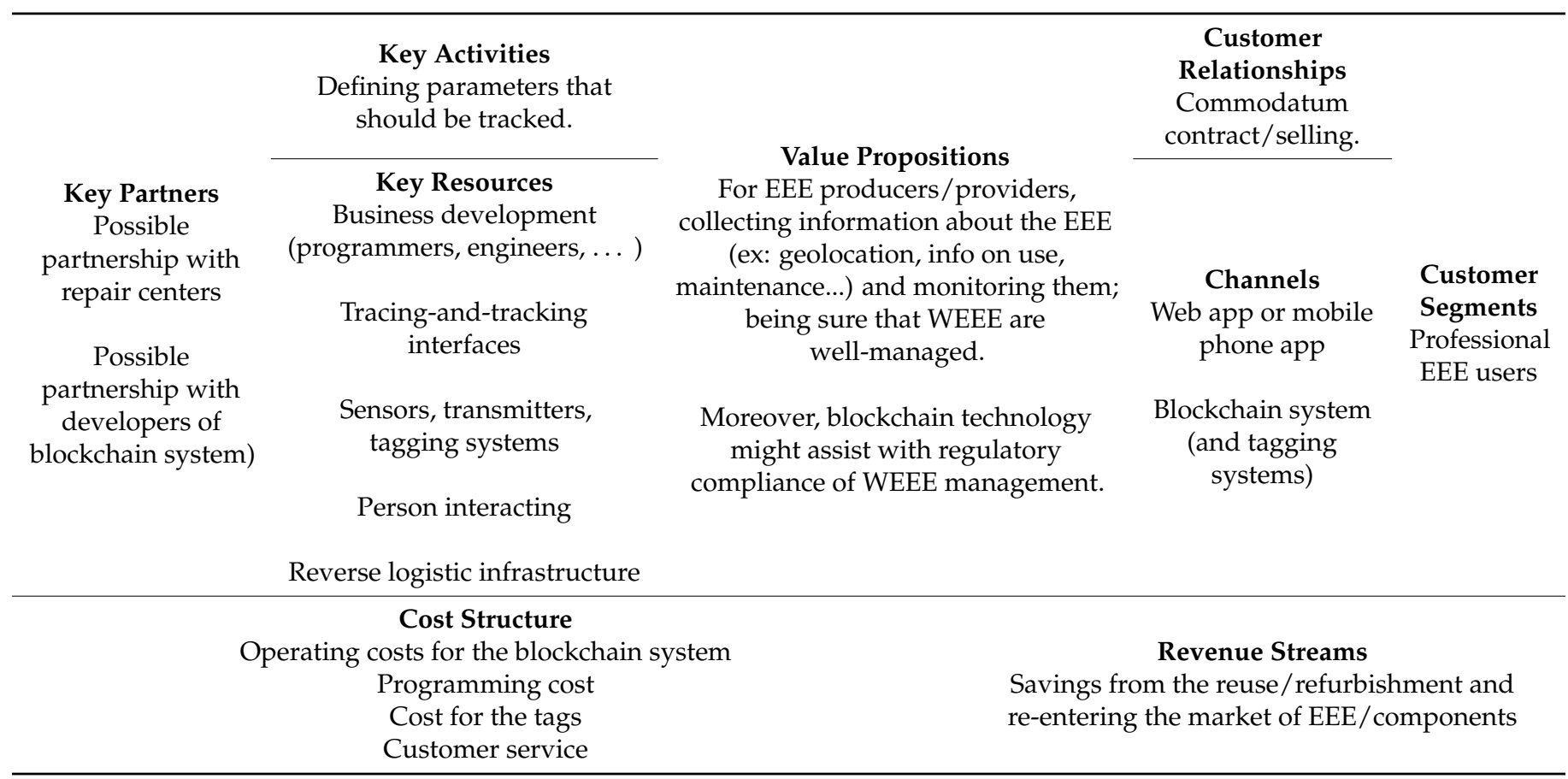

Table A2. Variation 2-Business model canvas.

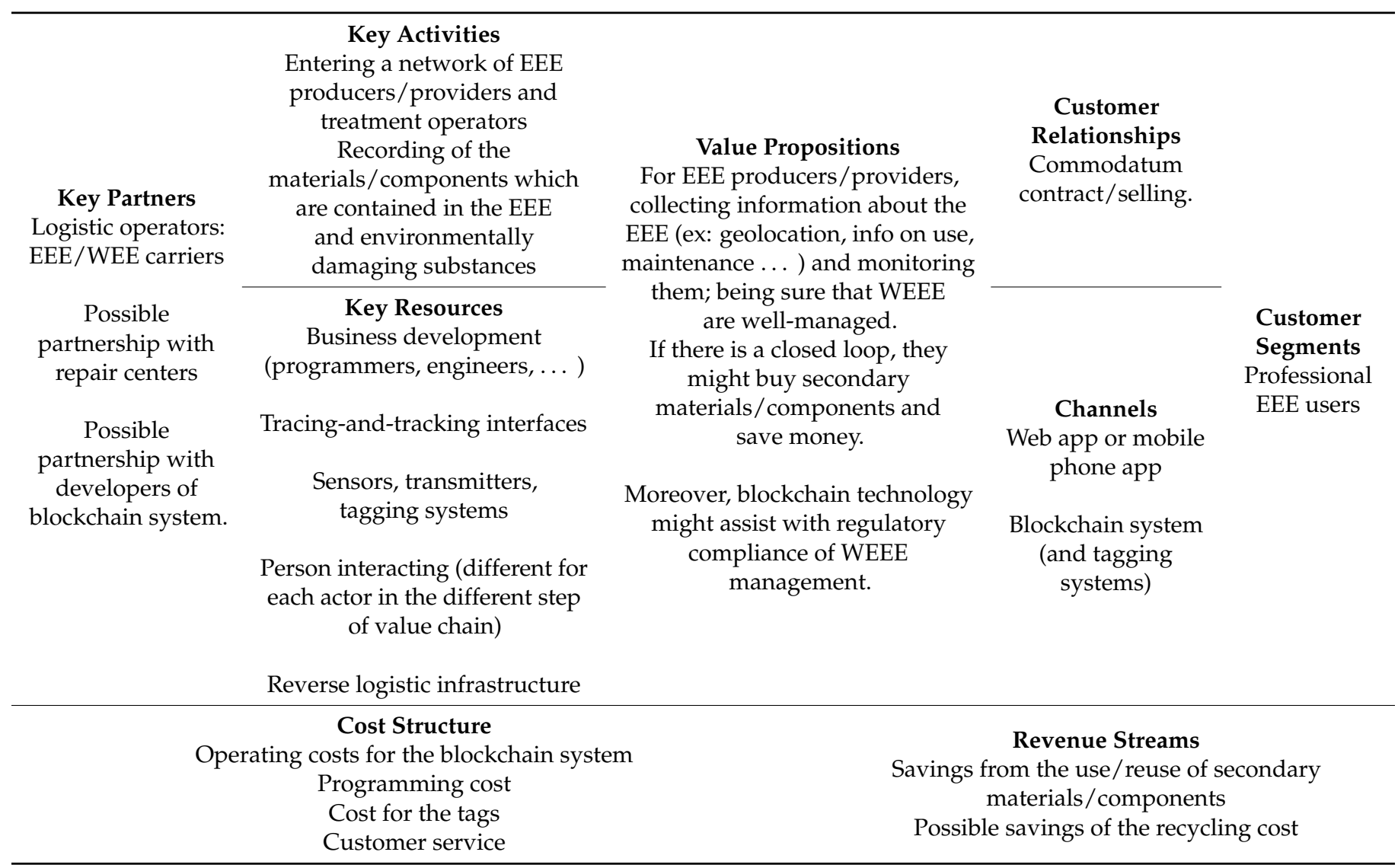


Table A3. Variation 3-Business model canvas.

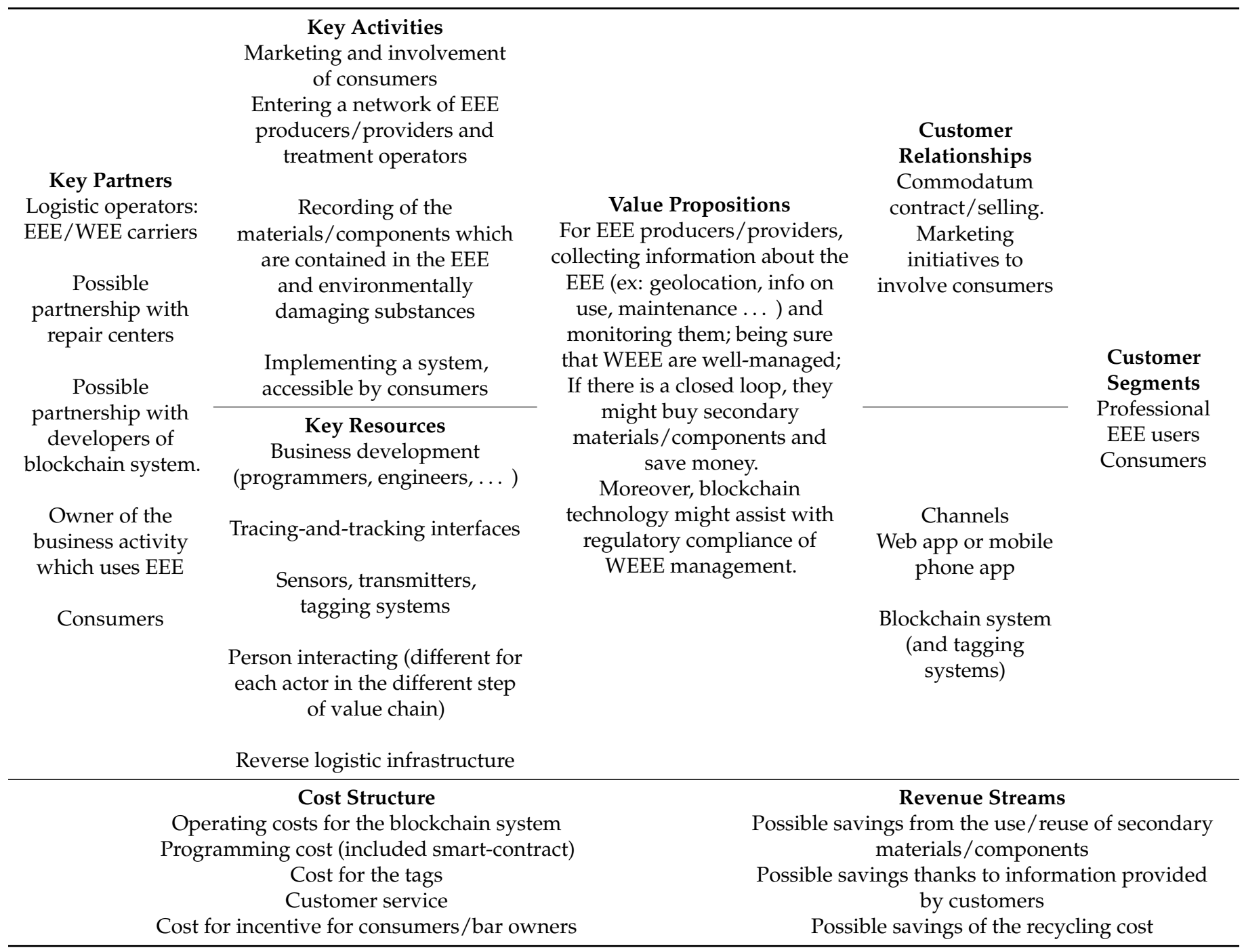

\section{References}

1. Material Economics. The Circular Economy - A Powerful Force for Climate Mitigation; Material Economics: Stockholm, Sweden, 2018.

2. Circle Economy. The Circularity Gap Report; Circle Economy: Amsterdam, The Netherlands, 2021.

3. Bressanelli, G.; Adrodegari, F.; Perona, M.; Saccani, N. The role of digital technologies to overcome Circular Economy challenges in PSS Business Models: An exploratory case study. Procedia CIRP 2018, 73, 216-221. [CrossRef]

4. Antikainen, M.; Uusitalo, T.; Kivikytö-Reponen, P. Digitalisation as an Enabler of Circular Economy. Procedia CIRP 2018, 73, 45-49. [CrossRef]

5. Demestichas, K.; Daskalakis, E. Information and Communication Technology Solutions for the Circular Economy. Sustainability 2020, 12, 7272. [CrossRef]

6. Rosa, P.; Sassanelli, C.; Urbinati, A.; Chiaroni, D.; Terzi, S. Assessing relations between Circular Economy and Industry 4.0: A systematic literature review. Int. J. Prod. Res. 2019, 58, 1662-1687. [CrossRef]

7. Wilts, H.; Berg, H. The Digital Circular Economy: Can the Digital Transformation Pave the Way for Resource-Efficient Materials Cycles? Wuppertal Institute: Wuppertal, Germany, 2017.

8. Climate-KIC. Digitalisation-Unlocking the Potential of the Circular Economy; White Paper; Climate-KIC: Brussels, Belgium, 2018.

9. Kristoffersen, E.; Blomsma, F.; Mikalef, P.; Li, J. The smart circular economy: A digital-enabled circular strategies framework for manufacturing companies. J. Bus. Res. 2020, 120, 241-261. [CrossRef]

10. Riesener, M.; Dolle, C.; Mattern, C.; Kres, J. Circular Economy: Challenges and Potentials for the Manufacturing Industry by Digital Transformation. In Proceedings of the 2019 IEEE International Symposium on Innovation and Entrepreneurship (TEMS-ISIE), Hangzhou, China, 24-26 October 2019; pp. 1-7.

11. Bressanelli, G.; Adrodegari, F.; Perona, M.; Saccani, N. Exploring How Usage-Focused Business Models Enable Circular Economy through Digital Technologies. Sustainability 2018, 10, 639. [CrossRef] 
12. Okorie, O.; Salonitis, K.; Charnley, F.; Moreno, M.; Turner, C.; Tiwari, A. Digitisation and the Circular Economy: A Review of Current Research and Future Trends. Energies 2018, 11, 3009. [CrossRef]

13. Pagoropoulos, A.; Pigosso, D.C.; McAloone, T.C. The Emergent Role of Digital Technologies in the Circular Economy: A Review. Procedia CIRP 2017, 64, 19-24. [CrossRef]

14. Kristoffersen, E.; Aremu, O.O.; Blomsma, F.; Mikalef, P.; Li, J. Exploring the Relationship Between Data Science and Circular Economy: An Enhanced CRISP-DM Process Model; Metzler, J.B., Ed.; Springer: Cham, Switzerland, 2019; pp. 177-189.

15. Forti, V.; Balde, C.P.; Kuehr, R.; Bel, G. The Global E-Waste Monitor 2020: Quantities, Flows and the Circular Economy Potential; United Nations University (UNU): Bonn, Germany; United Nations Institute for Training and Research (UNITAR)—Co-Hosted SCYCLE Programme: Geneva, Switzerland; International Telecommunication Union (ITU) \& International Solid Waste Association (ISWA): Rotterdam, The Netherlands, 2020.

16. Cole, C.; Gnanapragasam, A.; Cooper, T.; Singh, J. An assessment of achievements of the WEEE Directive in promoting movement up the waste hierarchy: Experiences in the UK. Waste Manag. 2019, 87, 417-427. [CrossRef]

17. Perkins, D.N.; Drisse, M.N.B.; Nxele, T.; Sly, P.D. E-Waste: A Global Hazard. Ann. Glob. Health 2014, 80, 286-295. [CrossRef]

18. Ellen MacArthur Foundation. Circular Consumer Electronics: An Initial Exploration; Ellen MacArthur Foundation: Cowes, UK, 2018.

19. Erbschloe, M. (Ed.) An Overview of Socially Responsible Information Technology Management. In Socially Responsible IT Management; Digital Press: Burlington, NJ, USA, 2003; pp. 1-13.

20. Centro di Coordinamento RAEE. GESTIONE RAEE 2019; Centro di Coordinamento RAEE: Milano, Italy, 2019.

21. OECD. Business Models for the Circular Economy: Opportunities and Challenges for Policy; OECD Publishing: Paris, France, 2019.

22. Eurostat. Waste Statistics_Electrical and Electronic Equipment; Eurostat: Luxembourg, 2019.

23. Song, M.-L.; Fisher, R.; Wang, J.-L.; Cui, L.-B. Environmental performance evaluation with big data: Theories and methods. Ann. Oper. Res. 2018, 270, 459-472. [CrossRef]

24. Dindarian, A.; Chakravarthy, S. Traceability of Electronic Waste Using Blockchain Technology. In Issues in Environmental Science and Technology; Royal Society of Chemistry (RSC): London, UK, 2019; Chapter 7; pp. 188-212.

25. Upadhyay, A.; Mukhuty, S.; Kumar, V.; Kazancoglu, Y. Blockchain technology and the circular economy: Implications for sustainability and social responsibility. J. Clean. Prod. 2021, 293, 126130. [CrossRef]

26. Kouhizadeh, M.; Sarkis, J. Blockchain Practices, Potentials, and Perspectives in Greening Supply Chains. Sustainability 2018, 10, 3652. [CrossRef]

27. Ellen MacArthur Foundation. Artificial Intelligence and the Circular Economy; Ellen MacArthur Foundation Report; Ellen MacArthur Foundation: Cowes, UK, 2019.

28. Esmaeilian, B.; Sarkis, J.; Lewis, K.; Behdad, S. Blockchain for the future of sustainable supply chain management in Industry 4.0. Resour. Conserv. Recycl. 2020, 163, 105064. [CrossRef]

29. Acquah, M.A.; Chen, N.; Pan, J.-S.; Yang, H.-M.; Yan, B. Securing Fingerprint Template Using Blockchain and Distributed Storage System. Symmetry 2020, 12, 951. [CrossRef]

30. Koptyra, K.; Ogiela, M.R. Imagechain-Application of Blockchain Technology for Images. Sensors 2020, 21, 82. [CrossRef]

31. Berg, H.; Ramesohl, S. Digital circular economy as a cornerstone of a sustainable European industry transformation. In White Paper-ECERA European Circular Economy Research Alliance-20 October 2020; VITO Mol: Brussels, Belgium, 2020.

32. Kamath, R. Food Traceability on Blockchain: Walmart's Pork and Mango Pilots with IBM. J. Br. Blockchain Assoc. 2018, 1, 1-12. [CrossRef]

33. Tian, F. An agri-food supply chain traceability system for China based on RFID \& blockchain technology. In Proceedings of the 2016 13th International Conference on Service Systems and Service Management (ICSSSM), Kunming, China, 24-26 June 2016. [CrossRef]

34. Tian, F. A supply chain traceability system for food safety based on HACCP, blockchain \& Internet of things. In Proceedings of the 2017 International Conference on Service Systems and Service Management, Dalian, China, 16-18 June 2017; pp. 1-6.

35. Caro, M.P.; Ali, M.S.; Vecchio, M.; Giaffreda, R. Blockchain-based traceability in Agri-Food supply chain management: A practical implementation. In Proceedings of the 2018 IoT Vertical and Topical Summit on Agriculture-Tuscany (IOT Tuscany), Tuscany, Italy, 8-9 May 2018; pp. 1-4.

36. Mitani, T.; Otsuka, A. Traceability in Permissioned Blockchain. IEEE Access 2020, 8, 21573-21588. [CrossRef]

37. Kouhizadeh, M.; Zhu, Q.; Sarkis, J. Blockchain and the circular economy: Potential tensions and critical reflections from practice. Prod. Plan. Control. 2019, 31, 950-966. [CrossRef]

38. Lüdeke-Freund, F.; Gold, S.; Bocken, N.M.P. A Review and Typology of Circular Economy Business Model Patterns. J. Ind. Ecol. 2018, 23, 36-61. [CrossRef]

39. Osterwalder, A.; Pigneur, Y. Business Model Generation: A Handbook for Visionaries, Game Changers, and Challengers; John Wiley \& Sons: Hoboken, NJ, USA, 2010.

40. Magrini, C.; Degli Esposti, A.; De Marco, E.; Bonoli, A. A framework for sustainability assessment and prioritisation of urban waste prevention measures. Sci. Total. Environ. 2021, 776, 145773. [CrossRef] [PubMed]

41. Mugge, R.; Schoormans, J.P.L.; Schifferstein, H.N.J. Design Strategies to Postpone Consumers' Product Replacement: The Value of a Strong Person-Product Relationship. Des. J. 2005, 8, 38-48. [CrossRef]

42. Bardhi, F.; Eckhardt, G.M. Access-Based Consumption: The Case of Car Sharing: Table 1. J. Consum. Res. 2012, 39, 881-898. [CrossRef] 
43. Bocken, N.M.; Mugge, R.; Bom, C.A.; Lemstra, H.-J. Pay-per-use business models as a driver for sustainable consumption: Evidence from the case of HOMIE. J. Clean. Prod. 2018, 198, 498-510. [CrossRef]

44. Lantto, R.; Tähtinen, M.; Järnefelt, V.; Jääskeläinen, A.-S.; Laine-Ylijoki, J.; Oasmaa, A.; Sundqvist-Andberg, H.; Sözer, N. Going Beyond a Circular Economy; VTT Technical Research Centre of Finland: Espoo, Finland, 2018.

45. Magrini, C.; D'Addato, F.; Bonoli, A. Municipal solid waste prevention: A review of market-based instruments in six European Union countries. Waste Manag. Res. 2020, 38, 3-22. [CrossRef]

46. Aksin-Sivrikaya, S.; Bhattacharya, C.B. Where Digitalization Meets Sustainability: Opportunities and Challenges. In Sustainability in a Digital World; CSR, Sustainability, Ethics \& Governance; Springer: Berlin/Heidelberg, Germany, 2017.

47. Chen, M.; Ogunseitan, O.A. Zero E-waste: Regulatory impediments and blockchain imperatives. Front. Environ. Sci. Eng. 2021, 15, 1-10. [CrossRef]

48. Hedberg, A.; Šipka, S.; Bjerkem, J. The Circular Economy: Going Digital; European Policy Center: Brussels, Belgium, 2020.

49. Acatech; Circular Economy Initiative Deutschland; SYSTEMIQ (Eds.) Circular Business Models: Overcoming Barriers, Unleashing Potentials; Acatech: Munich, Germany; SYSTEMIQ: London, UK, 2020. 